\title{
Integrating First-Year Convocation into the Orientation Experience: Innovative Strategies to Enhance the Experience
}

\author{
Natasha Lovelace Habers, M.F.A., Kennesaw State University \\ Ruth Ann Goldfine, Ph.D., Kennesaw State University \\ Deborah Mixson-Brookshire, Kennesaw State University \\ Alison Hedrick, Kennesaw State University
}

First-Year Convocation ceremonies, also known as induction ceremonies, are often held by colleges and universities to welcome the incoming class of first-year students. The traditional model for Convocation is typically a formal ceremony that mimics commencement. After years of Convocation ceremonies that followed this traditional model, the authors' institution successfully incorporated innovative strategies to enhance their Convocation ceremony by collaborating with campus partners, integrating engaging and interactive elements as part of and surrounding the event, and adopting a data-informed approach to modifying the ceremony in order to enhance the experience for attendees.

First-Year Convocation ceremonies, also known as induction ceremonies, are large gatherings held by colleges and universities at the start of each fall semester to welcome the incoming class of first-year students. Convocation serves as the bookend for commencement and brings together the campus community to officially welcome the newest cohort of students into

the university's community of scholars. Typically presided over by the president of the institution or another high-ranking administrator, Convocation provides the opportunity for administrators and faculty to engage with students in a formal academic gathering and sets the tone for their college experience. Convocation ceremonies, which may function as the capstone to students' orientation experience or kick off an institution's week 
of welcome events, are generally designed to facilitate students' transition to college by fostering institutional affinity, creating a sense of community, and officially inducting students into the university's community of scholars.

A traditional First-Year Convocation ceremony often adheres to an established formula that mimics Commencement. The event gathers students, their families, and the campus community in a formal, isolated event that is presided over by the President and features a keynote speaker. After years of Convocation ceremonies that followed this traditional model, we sought to innovate the Convocation experience at our institution by collaborating with campus partners, integrating engaging and interactive elements into the event, and adopting a data-informed approach to modifying the ceremony in order to enhance the experience for attendees.

At our institution, the planning of First-Year Convocation falls under the purview of an academic college that houses both a department dedicated to serving first-year students and the Orientation Office. Given the gulf that often exists between Academic Affairs and Student Affairs on college campuses, one of our most impactful innovations surrounding Convocation was the purposeful inclusion of an expanded group of personnel from both Academic Affairs and Student Affairs in the planning of this event. Specifically, we reached out to our campus partners in Student Affairs to collaborate in ways that allowed us to expand the isolated Convocation ceremony to a full-day experience designed to engage students and their families.

As a result of this collaboration, First-Year Convocation has been integrated into the Week of Welcome activities hosted by Student Affairs, and our campus now provides students with a comprehensive offering of studentcentered orientation and transition activities that complement and enhance - rather than compete with - one another. Notably, Convocation, now the signature event for the Week of Welcome, affords the opportunity to include family members in students' transition to college amidst a week of activities that largely cater to the students themselves. This partnership has been mutually beneficial and allows for a more coordinated approach to helping students transition to college.

In order to make First-Year Convocation itself more robust and interactive for students and their families, we modified the formal student induction 
portion of Convocation to include a pinning ceremony. Midway through Convocation, following the keynote speaker's address, the University President asks the first-year students to stand and leads them in a recitation of the Owl Creed - our university's matriculation pledge. At the conclusion of the recitation, the President invites students to place on their lapels a pin that was provided to them as they entered the auditorium prior to the start of the event. The pin, uniquely designed for this induction ceremony, includes our institution's logo as well as the words "lighting paths of love and learning," which are taken from our Alma Mater. These pins, available only to those firstyear students who attend Convocation, have become cherished mementos that many students choose to wear on their gowns when they walk across the stage at graduation.

Another interactive innovation for students and their families that we connected to Convocation was an aerial photo. At the conclusion of the Convocation ceremony, the University President invites all attendees students, family members, faculty, staff - to participate in an aerial photograph to commemorate the students' transition to college. The photograph, which is staged on the campus green immediately outside the auditorium, requires attendees to physically stand inside the outline of letters painted on the campus green (which form the three-letter acronym of our institution) while a photographer from our public relations office is positioned in a helicopter overhead to take the photo. While the aerial photo itself visually records this once-in-a-lifetime event, the active participation of first-year students in staging the photograph places them, both physically and symbolically, within our institution and its community of scholars. The inclusion of first-year students in this lasting, highly visible artifact provides students and their families with a tangible memento they can view and reflect upon throughout their academic years and beyond. The success and popularity of this aerial photograph is evident from attendee feedback and from the frequency with which the photograph is used to represent our institution in videos clips, print matter, and social media. 


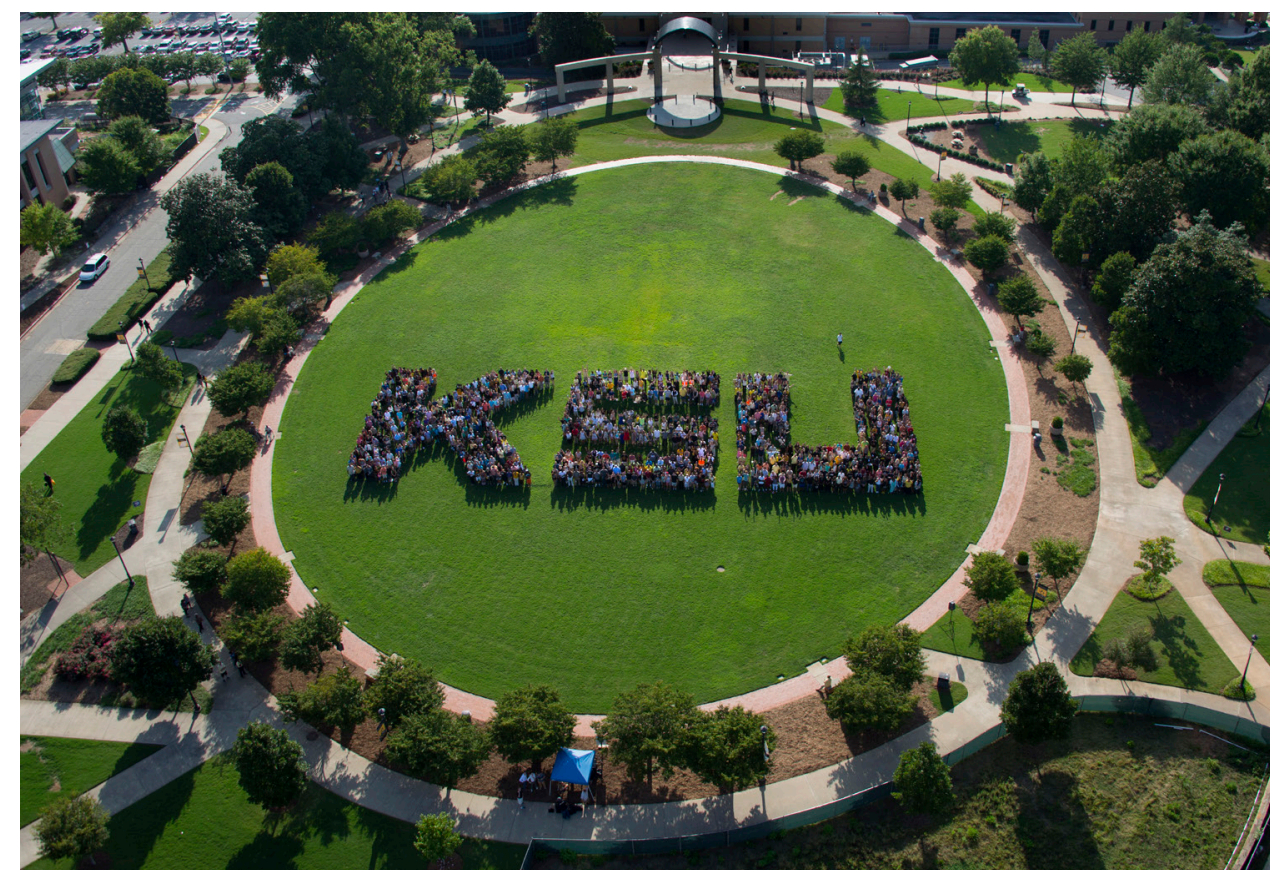

2nd Annual First-Year Convocation Aerial Photo, KSU Campus Green.

Perhaps the most significant and valuable innovation regarding First-Year Convocation on our campus has been the collection of data about Convocation through a longitudinal research study. This study gathered data about the Convocation experience from all attendees - students, family members, faculty, and staff - through post-event surveys. The findings from the study guided our efforts to identify areas of needed improvement, enhance the Convocation ceremony itself as well as pre- and post-Convocation activities, and provide a meaningful experience for attendees. Another significant finding was the attendees' preference of keynote speaker. Our research study revealed that the attendees preferred a speaker who was a recent graduate from our institution (typically within the past five years) rather than a high profile figurehead, such as those who had been brought in as Convocation keynotes in previous years. The results of the study also influenced our timing of the event, particularly the day of the week and the time of day. Specifically, we discovered that the optimum time to hold Convocation was within a week following the first day classes, rather than prior to the start of classes, which had been the common practice at our institution. Additionally, attendees indicated their 
preference for the event to be held on a Friday afternoon; Saturday was cited the next best day, and Sunday was the least popular option. Another key finding from our research was that First-Year Convocation helped to foster students' sense of belonging at our institution. This is significant because a sense of belonging has been shown to contribute to the retention of students at college. Other valuable findings from our research helped us to identify the most successful marketing strategies, demonstrated the effectiveness of the event (i.e., measured attendees' perceived purpose of the event as compared to our intended purpose), and revealed attendees' reason for deciding to attend Convocation. The tables and graphs below illustrate the findings of our research in more detail.

\section{Figure 1. Why did you attend?}

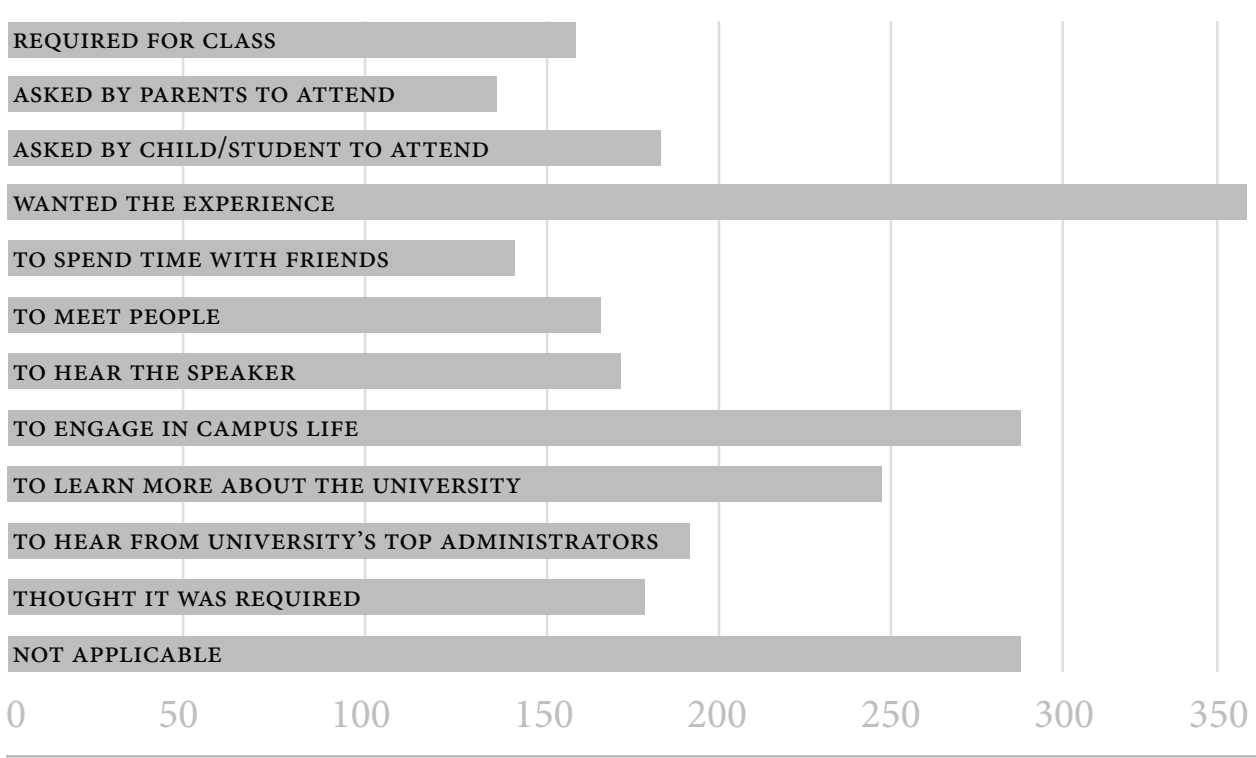




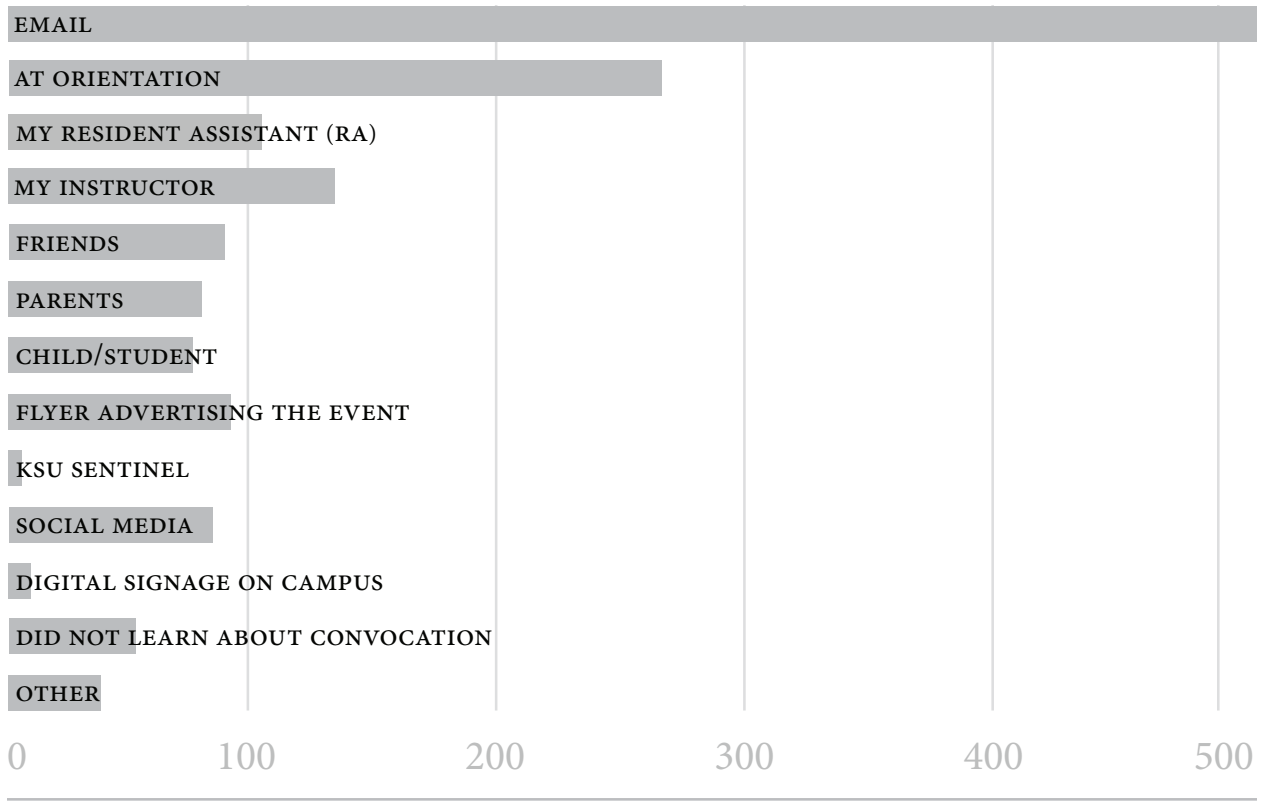

\section{Figure 3. Select Student Quotes from Longitudinall Study}

"It motivates me to do well in school. I can achieve anything I want."

"The First-Year Convocation solidified that not only was I about to initiate a new chapter of my life, but I was attending a university that cared about my academic growth and recognized the significance of this new chapter."

"It was fun to see all the excitement in the auditorium. Plus the aerial photo was a neat thing to do. Not everyone gets to be a part of history like that."

"I felt a sense of belonging when I was sitting with the group of kids my age all there for one reason. It made me realize that KSU is the perfect college for me and that I love it here."

"Convocation made me feel officially part of the student body here. Seeing our parents, administrators, and RAs up in the stands cheering for us made me prideful, excited, and hopefuly of the future and being a student at KSU." 
Figure 4. What is the purpose of First-Year Convocation?

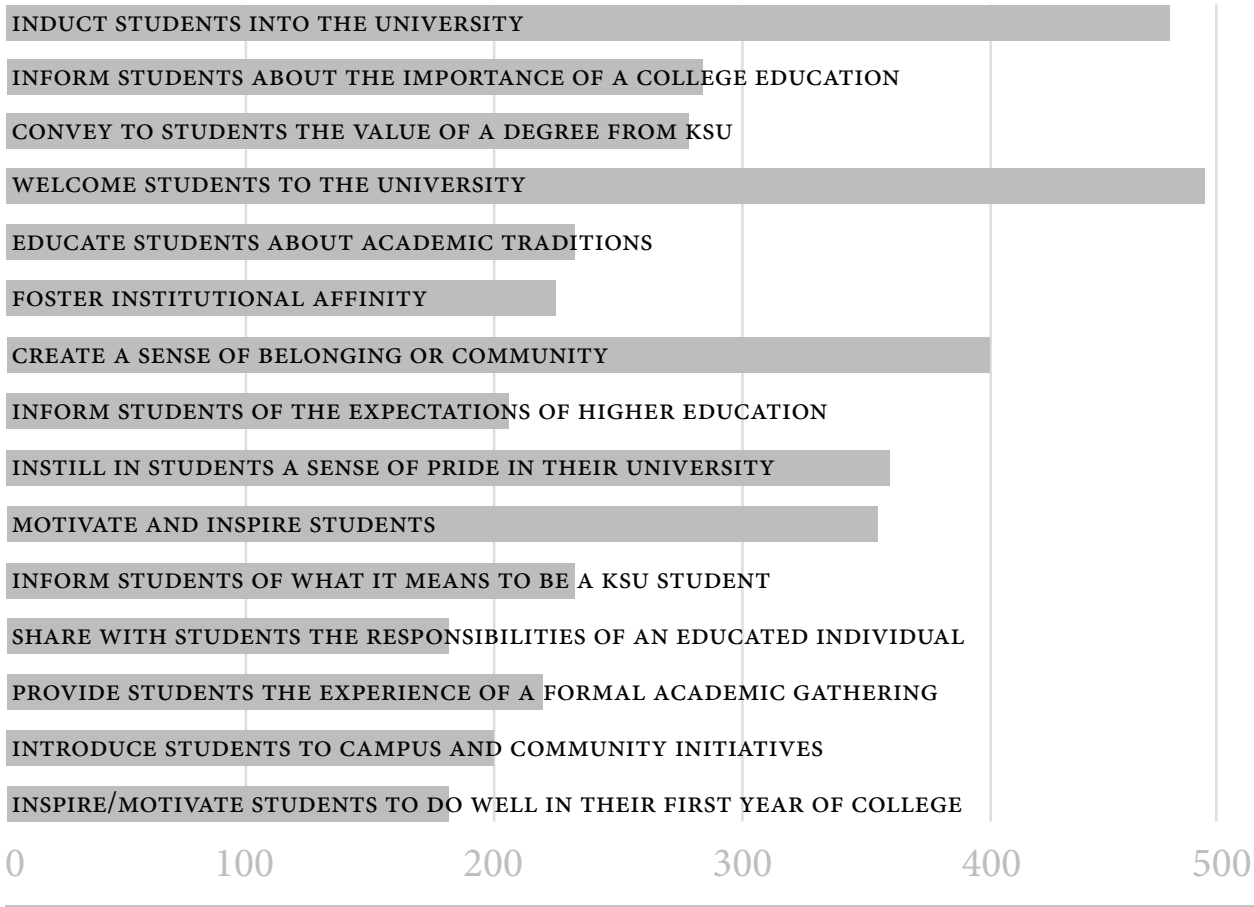

The successful innovations we implemented to enhance the First-Year Convocation at our institution have had numerous positive results. Our collaboration with Student Affairs has resulted in Convocation becoming a signature event during the Week of Welcome and has led to a more intentional and coordinated series of events and activities for our new students and their families. The integration of interactive elements - such as the induction pinning ceremony and the aerial photo - has led to greater engagement on the part of students and their families in lasting and meaningful ways. Finally, the longitudinal data gathered through our study of the First-Year Convocation ceremony at our institution has provided a wealth of knowledge for improving the event and better engaging with our students.

Whether it is the culminating experience of first-year students' orientation to college or it serves as part of a broader effort to successfully transition students into the campus culture, First- Year Convocation has the potential to impact student retention at college by fostering a sense 
of belonging and institutional affinity. Consequently, institutions are welladvised to reimagine their first-year convocation ceremonies as retention initiatives and contemplate innovations such as those described above. Other innovations that institutions might consider to enhance their firstyear convocation ceremony and foster student engagement - with the goal of supporting orientation and transition efforts and, ultimately, improving retention - include:

- Formation of a campus-wide planning committee that includes representatives from Academic Affairs and Student Affairs

- A "class of" march across campus to the convocation ceremony

- Inclusion of the marching band as part of the event

- Open-house type gatherings for various campus units before or after Convocation

- A student organization fair as a pre- or post-Convocation event

- Dining options on campus that are available to both students and their families before or after Convocation

- Creation of a promotional video to market the event via social media and at orientation

The findings of our research and the recommendations provided above may prove valuable to those institutions wishing to begin, reevaluate, or modify the First-Year Convocation - or similar induction ceremonies - at their institutions. Additional research on these ceremonies and their impact on attendees would be valuable in helping to direct and shape the design and logistics of these events. 